This PDF is a selection from a published volume from the National Bureau of Economic Research

Volume Title: Research Findings in the Economics of Aging

Volume Author/Editor: David A. Wise, editor

Volume Publisher: The University of Chicago Press

Volume ISBN: 0-226-90306-0

Volume URL: http://www.nber.org/books/wise08-1

Conference Dates: May 10-13, 2007

Publication Date: February 2010

Chapter Title: The Narrowing Dispersion of Medicare Expenditures 1997 to 2005

Chapter Author: Jay Bhattacharya, Alan M. Garber, Thomas MaCurdy

Chapter URL: http://www.nber.org/chapters/c8212

Chapter pages in book: (387 - 407) 


\title{
The Narrowing Dispersion of Medicare Expenditures 1997 to 2005
}

\author{
Jay Bhattacharya, Alan M. Garber, and \\ Thomas MaCurdy
}

\subsection{Introduction}

The projected gap between Medicare revenues and expenditures has growing immediacy with the implementation of the Part D drug benefit and the looming bankruptcy of the Hospital Insurance Trust Fund, which is used to make Medicare Part A payments. However, concerns about the sustainability of Medicare are not new, and over the past twenty-five years several important legislative initiatives to control the growth in Medicare spending have been passed into law. The adoption of Medicare's Prospective Payment System in the 1980s, for example, not only transformed the hospital care of Medicare patients, but influenced hospital reimbursement by private payers as well. Among the most far-reaching legislative initiatives since then was the passage of the Balanced Budget Act (BBA) of 1997.

Most of the changes in the BBA were intended to cut reimbursements rather than to change mechanisms of payment, but they were more than minor modifications of existing payment policies. The changes included direct reductions to the Prospective Payment System (PPS) inpatient hospital annual operating update and PPS inpatient capital payments, affect-

Jay Bhattacharya is an associate professor of medicine at Stanford University School of Medicine and a research associate of the National Bureau of Economic Research. Alan M. Garber is a staff physician at the VA Palo Alto Health Care System; director of the Center for Health Policy and Center for Primary Care and Outcomes Research (CHP/PCOR), and the Henry J. Kaiser, Jr. Professor and Professor of Medicine as well as Professor, by courtesy, of Economics, of Health Research and Policy, and of Economics in the Graduate School of Business, Stanford University; and a research associate of the National Bureau of Economic Research. Thomas MaCurdy is a professor of economics at Stanford University, a senior fellow at the Hoover Institution, and a research associate of the National Bureau of Economic Research. 
ing nearly all hospitals that cared for Medicare inpatients. Cuts in indirect medical education (IME) payments and direct medical education (DME) payments were felt by teaching institutions, while changes in formulas for disproportionate share (DSH) payments had their greatest effects on hospitals that cared for the indigent and uninsured. The BBA also expanded the Medicare transfer policy (which reduces payments for transfers of shortterm acute patients in ten Diagnosis Related Groups who were discharged to a Skilled Nursing Facility, PPS-exempt facilities, or to a home health agency). There were also changes in the structure of payment, such as the implementation of prospective payment systems for outpatient hospital, skilled nursing facilities, and home health agencies, and the creation of Medicare + Choice managed care plans, with efforts to improve geographic adjustments to payments for such plans.

Although not all the BBA features were implemented immediately, and its provisions were modified - and in some cases, weakened - in the Balanced Budget Refinement Act (BBRA) of 1999, its effects were felt by hospitals and other providers. Reportedly hospital margins shrunk, and home health service used dropped dramatically, with a large reduction in the number of home health service providers (Wilensky 2000).

The BBA effects on hospitals may be difficult to assess fully because there were contemporaneous changes in payments from private insurers, many working in the same direction. We seek here to investigate how BBA may have affected trends in Medicare expenditures for beneficiaries. At least in the immediate post-BBA period, the most important effects were on inpatient services and home health services, where the intention was unambiguously to reduce Medicare payments. Other features, such as the introduction of prospective payment for some outpatient services and the creation of Medicare + Choice plans, were clearly intended to provide new payment mechanisms with the prospect for long-term expenditure control, but were not necessarily designed to reduce near-term expenditures.

Our interest focuses on the effects of BBA on the dispersion of Medicare expenditures. That is, we seek to learn whether following the implementation of the BBA expenditures grew more or less rapidly for high-expenditure Medicare beneficiaries than for people who used few Medicare-covered services. The growth in per-beneficiary expenditures slowed after implementation of the BBA but its effects on the dispersion of expenditures have been little studied. In particular, did the BBA selectively reduce cost growth at the high end, where many of its features were directed? Did growth slow evenly among all Medicare beneficiaries? And were the effects different for men and women, or blacks and whites? The changes in disproportionate share payments, for example, would have been felt predominantly by hospitals providing care for the poor, and thus might have led to greater changes in expenditures for blacks than whites.

We describe changes in cohort patterns of expenditures between 1997 and 
2005, describing growth in per capita expenditures at different percentiles for different subgroups.

\subsection{Data and Methods}

Our primary data source is the Medicare Beneficiary Annual Summary File (BASF). The BASF is a data set that contains comprehensive information on Medicare expenditures for 100 percent of all Medicare enrollees who are not enrolled in a Medicare Advantage (HMO) plan. Expenditures include all sources of Medicare expenditures, including Part A, Part B, physician expenditures, home health expenditures, and skilled nursing facilities (thought not Part D, since it was not implemented until 2006). The BASF also includes a comprehensive set of chronic disease indicators for each individual in the file. No individual leaves our sample until death.

\subsubsection{Description of the Data}

The BASF data are derived from annual enrollment and claims data collected by the Centers for Medicare and Medicaid Services (CMS). These are administrative data used by CMS to verify eligibility and to process hospital and physician claims for payment on behalf of Medicare beneficiaries. Enrollment data capture eligibility and demographic information at a pointin-time (typically July 1st of each calendar year). Claims data are requests for payment for a particular service provided during a given period of time, and they include information on the ICD-9-CM diagnosis and procedure codes, CPT-4/HCPCS codes, revenue center codes, provider type/specialty, Medicare reimbursement, third-party payments, beneficiary copayments, and deductibles. Claim formats vary depending on the type of provider and whether the claims were processed by a fiscal intermediary (hospital insurance under Part A) or a carrier (supplemental medical insurance under Part B). Only those beneficiaries enrolled in Medicare fee-for-service generate claims data.

Claims data in raw format are not useful for analyses of beneficiary utilization and expenditures over time because such an analysis requires aggregating enrollment, service use, program payments, and beneficiary payments across claims, service types, and dates of service. Information on diagnoses and procedures need to be summarized for analyses of beneficiaries with particular conditions and treatments. Enrollment data capturing point-intime status must be validated and made consistent to reflect continuous enrollment status in Medicare fee-for-service and managed care.

To convert these data into a format useful for conducting analyses of beneficiary utilization and expenditures over time, we created utilization and expenditure files that summarize data on all nonmanaged care Medicare beneficiaries in each year between 1997 and 2005 inclusive. These data contain the beneficiaries' enrollment status, including Part A and Part B 
enrollment and mortality using date of death information from linked Social Security records. These data also contain utilization and expenditure data by service type, including inpatient hospital, skilled nursing facility (SNF), home health agency, hospice, outpatient hospital, physician (including clinical lab), and durable medical equipment. Expenditure data include Medicare program payments, third-party payments, and beneficiary payments (copayments and deductibles), with indicators supplied signaling assigned diagnosis-related group (DRG) (for inpatient hospital and SNF) or principal diagnosis (home health, outpatient hospital, and physician). In this chapter, we focus our attention on total Medicare expenditures per capita, which is a sum of expenditures from all these categories over the whole year.

\subsubsection{Chronic Disease Indicators}

For some of our analyses, we need detailed information on the health status of Medicare patients. Rather than rely on self-reports, we instead use diagnostic code data in claims records to generate objective information on the presence of chronic disease. This information is derived from looking at patterns of longitudinally-linked claims records for a single individual. The basic idea in deriving chronic condition indicators is that if an individual has a past claim with the diagnosis listed, then that individual can be presumed to have that chronic condition. The procedures associated with implementing this basic idea obviously involve a lot of attention to detail, however.

For the purpose of creating risk adjustment scores for payment to managed care programs, CMS has endorsed a methodology for assigning chronic disease indicators (called hierarchical conditional categories, or HCCs). We adopt this methodology to develop chronic disease indicators here. Pope et al. (2004) describe this methodology in some detail; we refer interested readers there, focusing here on only a few important details.

To assign HCCs for a Medicare enrollee in 1997, we examine diagnostic codes in Medicare claims in the prior two years. Once an enrollee is assigned a chronic disease indicator, that same enrollee is recorded with the same indicator in subsequent years. The list of conditions is derived from a longer and more detailed list of chronic conditions called CCs, which is itself derivative of the well-known ICD-9 coding system.

Clearly, this method of assigning chronic disease indicators is imperfect. Biases can arise from many different sources. In the 1970s, when large administrative data sets recording hospital claims data for patient discharges first became available, it was natural for researchers to want to use them to estimate some outcomes of interest, such as mortality rates associated with particular diseases. However, distrust of coding accuracy, given empirical backing by a series of influential studies by the Institute of Medicine (1977a, 1977b, 1980), likely played a role in discouraging investigators from using these data sets in such a manner. One of these studies (Institute of Medicine 1977b) found for the National Hospital Discharge Survey that the discharge 
diagnosis listed in the data set agreed with a controlled, expert reabstraction of the medical chart only an average of 73.2 percent of the time. Qualitatively similar results were found for Medicare claims data.

With the introduction of the prospective payment system and DRG reimbursement for Medicare claims, the additional concern arose that hospitals might game the reporting of patient diagnosis in order to increase payment for cases. Hsia et al. (1988) found that for a sample of 7,050 Medicare case records from 239 hospitals, the reabstracted diagnosis disagreed with that in the data set 20.8 percent of the time. Of these discrepancies, a statistically significant 61.7 percent favored the hospital financially. Additionally, Iezzoni et al. (1988) found that for a set of records from fifteen Boston hospitals, cases that presented as potential acute myocardial infarction (AMI) were commonly recorded as AMI even if further investigation revealed some other disease process. This was especially common for tertiary care teaching hospitals.

Recent scholarship has been cautiously optimistic about the improving quality of the Medicare administrative database diagnostic information. For example, another case record reabstraction study conducted by Fisher et al. (1992) explicitly attempted to replicate the Institute of Medicine study with the 1985 Medicare claims database. They found that the accuracy had modestly improved by 5 percentage points, relative to the earlier study.

While reabstraction studies have generally found diagnostic discrepancies on the order of 20 percent or more, the Medicare data set has performed better when other approaches are used to verify its external validity. Using Medicare claims and enrollment data from 1983 to 1986, Whittle et al. (1991a) estimated the incidence rate of breast, lung, and colon cancer and the rate of their surgical resection among the elderly population. They compared these estimates to those derived independently using a different survey instrument by the National Cancer Institute's Surveillance, Epidemiology, and End Results (SEER) program. The SEER data come from nine regional registries, accounting for 10 percent of the U.S. population. They found that the Medicare incidence rates were within 6 percent of SEER estimates, but that Medicare resection rates were 12 percent to 27 percent lower than SEER rates. One possible explanation for the discrepancy in resection rates is that practice patterns outside of SEER regions differ from those inside. However, they found that the Medicare resection estimates within SEER regions are not statistically different from those outside SEER regions for lung and colon cancer.

McBean, Babish, and Warren (1993) also estimated lung cancer incidence from Medicare data and compared the result to SEER estimates for the years 1986 to 1987 . With the assumption that SEER estimates have no sampling variance, they found that SEER identified a statistically significant 5.9 percent more cases than did Medicare. However, the population incidence estimates were similar, with 274.2/100,000 calculated for SEER and 
264.7/100,000 for the Medicare data. In contrast to Whittle et al. (1991a) they found that age-adjusted cancer incidence rates calculated using Medicare data were about 10 percent higher for patients residing outside SEER regions than inside.

In a more comprehensive study, McBean, Warren, and Babish (1994) repeated their previous work for the years 1986 to 1990, and for six different cancers. For breast, colon, lung cancer, and corpus uteri, they found that SEER and Medicare data estimates differed by less than 5 percent, while they differed by less than 8 percent for prostate and esophagus cancer. They found no uniform pattern in the differences between incidence rates inside and outside SEER regions. They concluded that Health Care Financing Administration (HCFA) data should be used to augment SEER monitoring of cancer incidence.

One potential explanation for the different conclusions reached by the reabstraction studies and the SEER studies is that while case abstracters may have trouble replicably assigning a very specific code, they have little problem assigning a broad diagnosis, like lung cancer. Hospitals are also less likely to misreport broad diagnostic designations for financial gain because the likelihood of detection by review agencies is higher than when fine diagnostic distinctions are misrepresented. If this is indeed the case, then studies using Medicare administrative databases to track broad diagnostic categories, such as HCCs, are more plausible than those that make use of finer diagnostic information.

These concerns aside, a large number of articles use Medicare Part A administrative data to estimate various epidemiological quantities of interest. Among such applications include estimates of: mortality rates after radical prostatectomy for prostate cancer patients (Mark 1994); in-hospital mortality after a stroke (May and Kittner 1994); resection rates and associated long-term mortality rates for colon cancer (Whittle et al. 1992) and lung cancer (Whittle et al. 1991b); post-myocardial infarction (MI) mortality rates, reinfarction rates, and likelihood of undergoing coronary artery bypass grafting $(\mathrm{CABG})$ and/or percutaneous transluminal coronary angioplasty (PTCA) (Udvarhelyi et al. 1992); and structural shifts in the mortality rates associated with CABG and PTCA over time (Peterson et al. 1994). Finally, this data set has been popular in the health services literature as well for myriad uses such as the estimation of regional variation in readmission rates for various diseases (Fisher et al. 1994) among many other applications. It is necessarily beyond the scope of this chapter to review all of these papers.

\subsubsection{Methods}

In this chapter, we track changes in the distribution of Medicare expenditures over the period 1997 to 2005 . Program payments are funds paid by the Medicare program on behalf of the beneficiary. Expenditures include 
third-party payments, in addition to beneficiary copayments and deductibles. Hereafter, we will refer to the sum of program payments and expenditures as simply expenditures. Among the statistics we track, we include mean expenditures as well as first, fifth, tenth, twenty-fifth, fiftieth, ninetieth, ninety-fifth, and ninety-ninth percentiles. We examine trends in the distribution of expenditures for different demographic and clinical subgroups of patients. To conduct these subgroup analyses, we first select all Medicare enrollees in each year that are members of the subgroup and then calculate summary statistics on expenditures for those members. We report changes in these summary statistics in two ways: absolute changes in real expenditures over the 1997 to 2005 period and per annum growth rates in expenditures. All results are reported in constant 2005 dollars.

In addition to trends in these summary statistics, we develop smoothed estimates of how the distribution of Medicare expenditures has changed over time. To track changes in mean expenditures, we estimate ordinary least squares (OLS) regression equations in which expenditures are a smooth function of the age of the respondent and the year of the observation. To track changes in the percentiles, we estimate quantile regressions (see Koenker and Hallock 2001) in which the key dependent variables are also smooth functions of age and year. In the remainder of this section, we make clear what we mean by "smooth functions." In this discussion, we will focus on how mean expenditure changes, but the smoothing method we use applies just as well in the quantile regression setting.

Constructing age-specific profiles of costs invariably runs into a problem of sample size. Even in a large, nationally representative sample such as the Medicare Current Beneficiary Survey (MCBS), the sample size at a single age turns out to be quite small to construct reliable estimates, especially for some of the smaller subgroup analyses that we conduct. To address this problem, we rely on the idea that Medicare expenditures should change smoothly across ages.

To describe the method we use to produce smooth age-specific prevalence functions - the overlap polynomial method ${ }^{1}$ - it is helpful to introduce some notation. Each observation $i$, taken in year ${ }_{i}$, consists of information about $i$ 's Medicare expenditures expend ${ }_{i}$ and age $_{i}{ }^{2}$ Given these data, we estimate the following model of Medicare expenditures:

$$
\text { expend }_{i}=c+g_{1}\left(\text { age }_{i}, \beta_{1}\right)+g_{2}\left(\text { year }_{i}, \beta_{1}\right) .
$$

The $g$ functions allow Medicare expenditures to flexibly vary with the year of observation and the age-cohort of the respondent. Age-cohort enters the model through $g_{1}$, which is specified using an overlap polynomial:

1. See MaCurdy, Green, and Paarsch (1990); MaCurdy and Garber (1993); and Bhattacharya, Garber, and MaCurdy (1997).

2. It is possible to adapt this method to use other covariates. 


$$
g_{1}\left(\operatorname{age}_{i}\right)=\sum_{j=0}^{K}\left(\Phi\left(\frac{\operatorname{age}_{i}-k_{j+1}}{\sigma_{1}}\right)-\Phi\left(\frac{\operatorname{age}_{i}-k_{j}}{\sigma_{i}}\right)\right) p_{j}\left(\operatorname{age}_{i} ; \beta_{1 j}\right),
$$

where $p_{j}\left(\right.$ age $\left._{i} ; \beta_{1 j}\right) j=0, \ldots, K+1$ are all $n$ th-order polynomial in age $e_{i}$. The knots are $k_{0} \ldots k_{K+1}$, and $\sigma_{1}$ is a smoothing parameter, which in addition to $n$, are all fixed before estimation. We use first-degree polynomials. Though we experimented with higher-order polynomials, we find that they add to the costs of computation with no change in the final projections.

With this smoothing technique, the knots define age intervals. When the smoothing parameter approaches zero, the age profile over each interval simply equals the within-interval average expenditures. In this case, the age profile reduces to a step function, where each step equals the within-interval average disability. ${ }^{3}$ As the smoothing parameter increases, the estimator uses increasingly more information from outside each interval. In the extreme, as the smoothing parameter approaches infinity, there is no meaningful distinction between any two intervals. Allowing nonzero values of the smoothing parameters eliminates the sharp discontinuity of the growth rates at the knots. One advantage of overlapping polynomials over traditional splines is that the function and all its derivatives are automatically continuous at the knots without imposing any parameter restrictions.

In addition to an overlap polynomial for age, we also include another overlap polynomial, $g_{2}$, for year to flexibly allow for changes in the ageprevalence relationship over time. Here, the knots are $m_{j}, j=0, \ldots, M$, the smoothing constant is $\sigma_{2}$, and $q_{j}$ are the polynomials. As before, experimentation led us to use first-order polynomials in year.

$$
g_{2}\left(\text { year }_{i}\right)=\sum_{j=0}^{M}\left(\Phi\left(\frac{\text { year }_{i}-m_{j+1}}{\sigma_{2}}\right)-\Phi\left(\frac{\text { year }_{i}-m_{j}}{\sigma_{2}}\right)\right) q_{j}\left(\text { year }_{i} ; \beta_{2 j}\right) .
$$

The object of the estimation is to obtain consistent estimates for $\beta_{1}$ and $\beta_{2}-\hat{\beta}_{1}$ and $\hat{\beta}_{2}$, respectively. Using these estimates, it is straightforward to generate age-specific expenditure profiles representative for any particular year. Let $\rho_{t, a}$ be the predicted expenditures among $a$-year olds in year $t$. Then,

$$
\rho_{t, a}=\frac{1}{N} \sum_{i}\left[\hat{c}+g_{1}\left(\operatorname{age}_{i}, \hat{\beta}_{1}\right)+g_{2}\left(\text { year }_{i}, \hat{\beta}_{2}\right)\right] .
$$

In some specifications, we are interested in how cohort profiles in Medicare expenditures have changed over time. For these specifications, we include interaction terms like:

3. When this is the case, $\Phi($.$) reduces to an indicator function equal to zero if age <k_{j}$ and one if age $\geq k_{j}$. Thus, the first term of the sum, $\left(\Phi\left(\left(\operatorname{age}_{i}-k_{1}\right) / \sigma_{1}\right)-\Phi\left(\left(\operatorname{age}_{i}-k_{0}\right) / \sigma_{1}\right)\right) p_{0}$, equals $p_{0}$ when $k_{0}<$ age $\leq k_{1}$, and zero otherwise. Between $k_{0}$ and $k_{1}$, the rate of disability is given by $p_{0}$, which in turn depends on the parameters $\beta_{1,0}$. 


$$
\begin{aligned}
& \sum_{j=0}^{M}\left(\Phi\left(\frac{\text { year }_{i}-m_{j+1}}{\sigma_{2}}\right)-\Phi\left(\frac{\text { year }_{i}-m_{j}}{\sigma_{2}}\right)\right) q_{j}\left(\text { age }_{i} ; \beta_{j}\right) \text { and } \\
& \sum_{j=0}^{M}\left(\Phi\left(\frac{\text { age }_{i}-m_{j+1}}{\sigma_{2}}\right)-\Phi\left(\frac{\text { age }_{i}-m_{j}}{\sigma_{2}}\right)\right) q_{j}\left(\operatorname{year}_{i} ; \beta_{j}\right) .
\end{aligned}
$$

Including terms like this is necessary because a specification like (1) imposes that cohort trends in expenditures are all parallel to each other. However, because age, cohort, and year are linearly related, it is not possible to estimate a full set of interaction terms. MaCurdy and Garber (1993) provide details on what restrictions are necessary and on how to recover cohort trends from specifications like the one shown previously.

\subsection{Results}

Table 13.1 shows how per capita expenditures on Medicare patients grew over the period 1997 to 2005. The BASF data confirm the finding from other data sources that per capita Medicare expenditures grew at 4.29 percent per annum over this period (see Bhattacharya and Lakdawalla 2006). Since all these figures are adjusted for inflation with the standard consumer price index, this represents a real growth in Medicare expenditures. This mean growth rate, however, hides important facts in the evolution of Medicare expenditures.

One of these facts, evident in table 13.1, is that the upper tail of the expenditure distribution actually shifted left between 1997 and 2000. The ninetieth percentile of the expenditure distribution decreased from \$15,348 in 1997 to $\$ 15,011$ in 2000 ; the ninety-fifth percentile decreased from $\$ 27,218$ to $\$ 26,556$; and the ninety-ninth percentile decreased from $\$ 59,325$ to $\$ 58,215$. Even mean expenditures declined between 1997 and 1999. Presumably these declines can be attributed to the effects of the 1997 Balanced Budget Act (BBA). The declines were short-lived, though. The expenditure distribution started shifting to the right in 2000 (after passage of the BBRA) and continued to do so in every percentile and in every year through 2005.

Despite the decline between 1997 and 2000, there has been growth in per capita Medicare expenditures across the whole distribution of expenditures (save the left tail) between 1997 and 2005. For instance, median per capita expenditures grew by $\$ 842$; the ninetieth percentile grew by $\$ 5,821$; and the ninety-ninth percentile grew by $\$ 74,808$. Looking at these absolute dollar increases alone, it would appear that there were larger increases at the upper end of the distribution than there were at the lower end. But as a proportion of initial 1997 expenditures for each percentile, the upper end of the distribution actually grew more slowly than the lower end. For instance, the median grew at 10.06 percent per annum while the ninetieth and ninetyninth percentiles grew at only 3.52 and 2.94 percent per annum. Median 


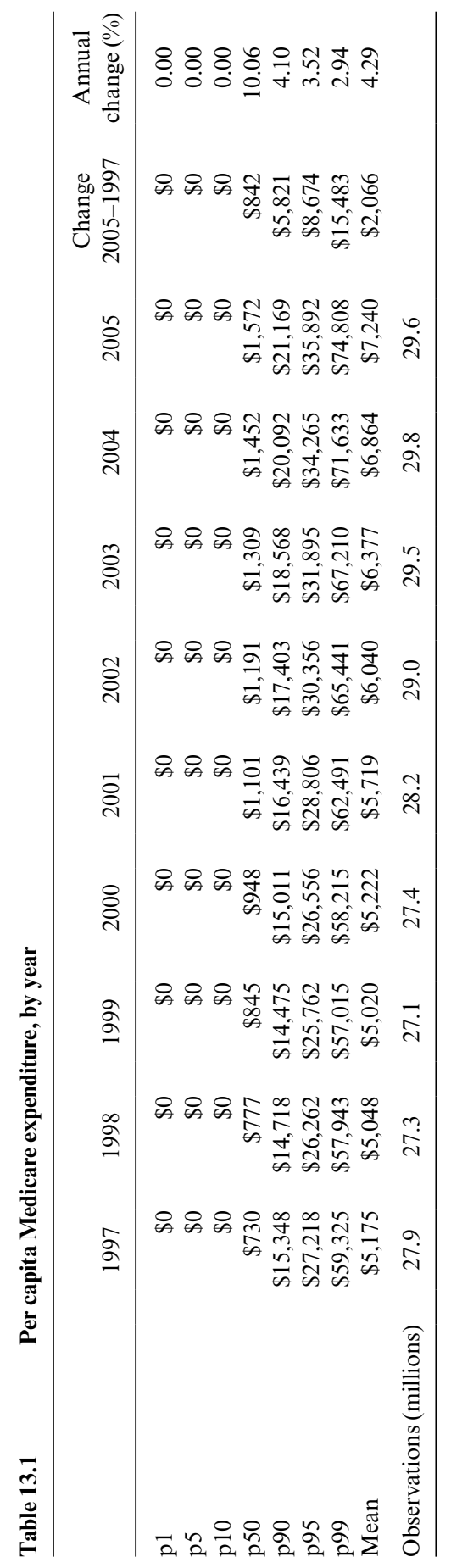


expenditures more than doubled over the 1997 to 2005 period. This was not the case for the upper percentiles.

The implications of these changes are that the Medicare per-capita expenditure distribution shifted to the right and that relative differences in expenditures between the lowest and highest parts of the distribution (leaving aside zeroes in the lowest percentiles) shrank. The fastest growth occurred in the middle of the distribution, while the upper end grew only modestly. This updates the trend reported by MaCurdy and Geppert (2005) for years prior to 1997. In one sense, inequality in Medicare expenditures has been declining: the distribution of per capita Medicare expenditures, conditional on having some expenditures at all, has been narrowing since 1997.

In another sense, inequality has been rising. Differences between expenditures for the care of black and white Medicare beneficiaries inequality has been increasing. Table 13.2, shows changes between 1997 and 2005 in the distribution of Medicare expenditures separately for black and white males and black and white females. For white males and white females, the real per annum mean growth rate in Medicare expenditures was 4.13 percent and 4.55 percent. By contrast, the analogous growth rates for black males and black females were 3.59 percent and 3.31 percent per annum. For whites, conditional on spending something, there was growth throughout the expenditure distribution. Given the results we report in table 13.1, it is unsurprising that the

Medicare expenditure, by sex and race

\begin{tabular}{|c|c|c|c|c|c|c|}
\hline & \multicolumn{2}{|c|}{ White } & \multicolumn{2}{|c|}{ Black } & \multicolumn{2}{|c|}{ Other race } \\
\hline & $\begin{array}{c}\text { Change } \\
2005-1997\end{array}$ & $\begin{array}{c}\text { Annual } \\
\text { change (\%) }\end{array}$ & $\begin{array}{c}\text { Change } \\
2005-1997\end{array}$ & $\begin{array}{c}\text { Annual } \\
\text { change (\%) }\end{array}$ & $\begin{array}{c}\text { Change } \\
\text { 2005-1997 }\end{array}$ & $\begin{array}{c}\text { Annual } \\
\text { change }(\%)\end{array}$ \\
\hline \multicolumn{7}{|c|}{ A Males } \\
\hline $\mathrm{p} 1$ & $\$ 0$ & 0.00 & $\$ 0$ & 0.00 & $\$ 0$ & 0.00 \\
\hline p5 & $\$ 0$ & 0.00 & $\$ 0$ & 0.00 & $\$ 0$ & 0.00 \\
\hline p10 & $\$ 0$ & 0.00 & $\$ 0$ & 0.00 & $\$ 0$ & 0.00 \\
\hline p50 & $\$ 785$ & 9.93 & $\$ 519$ & 9.98 & $\$ 416$ & 11.42 \\
\hline p90 & $\$ 5,721$ & 4.00 & $\$ 6,252$ & 3.42 & $\$ 5,236$ & 4.82 \\
\hline p95 & $\$ 8,526$ & 3.41 & $\$ 10,544$ & 3.32 & $\$ 8,631$ & 3.79 \\
\hline p99 & $\$ 16,225$ & 3.05 & $\$ 23,402$ & 3.30 & $\$ 18,148$ & 3.16 \\
\hline Mean & $\$ 1,997$ & 4.13 & $\$ 2,135$ & 3.59 & $\$ 1,823$ & 4.40 \\
\hline \multicolumn{7}{|c|}{ B Females } \\
\hline p1 & $\$ 0$ & 0.00 & $\$ 0$ & 0.00 & $\$ 0$ & 0.00 \\
\hline p5 & $\$ 0$ & 0.00 & $\$ 0$ & 0.00 & $\$ 0$ & 0.00 \\
\hline p10 & $\$ 39$ & n.a. & $\$ 0$ & 0.00 & $\$ 0$ & 0.00 \\
\hline p50 & $\$ 943$ & 10.30 & $\$ 840$ & 9.48 & $\$ 625$ & 10.26 \\
\hline p90 & $\$ 5,992$ & 4.34 & $\$ 5,315$ & 2.77 & $\$ 5,473$ & 5.06 \\
\hline p95 & $\$ 8,702$ & 3.70 & $\$ 8,570$ & 2.66 & $\$ 8,258$ & 3.78 \\
\hline p99 & $\$ 13,916$ & 2.84 & $\$ 19,199$ & 2.75 & $\$ 15,731$ & 2.94 \\
\hline Mean & $\$ 2,124$ & 4.55 & $\$ 2,089$ & 3.31 & $\$ 1,932$ & 4.65 \\
\hline
\end{tabular}


fastest growth for blacks and whites occurred at the middle of their respective distributions (about 10 percent per annum for whites and 9.5 to 10.3 percent per annum for blacks at the median). Growth was slower at the upper tails for everyone, though less in general for blacks than whites. To summarize, Medicare expenditure differences between blacks and whites grew over this period while the distribution of Medicare expenditures narrowed for each group.

Table 13.3 charts the increase in expenditures for men and women in different age groups rather than of different races. The most striking result in table 13.3 is that ninety-five-to ninety-nine-year-olds-both men and women - had the large increases in mean Medicare expenditures relative to younger Medicare populations between 1997 and 2005. For men, sixty-five to sixty-nine-year-olds had the smallest increase at the mean-3.67 percentage points per annum. For women, eighty-five to eighty-nine-year-olds had the smallest increase at the mean-3.84 percent per annum. For all agesex groups, the biggest proportionate increases in Medicare expenditures occurred in the lower end of the distribution (conditional on any expenditures). Indeed, eighty-five to eighty-nine-year-old men had an increase of 31.6 percent at the tenth percentile. Similarly, seventy- to seventy-four and ninety-five to ninety-nine-year-old women and ninety- to ninety-four-yearold men at the tenth percentile spent nothing in 1997 but spent positive amounts in 2005.

Table 13.4 offers another perspective on the relationship between aging and per capita Medicare expenditures. We organize the data by cohort of birth (rather than by age), and we follow the expenditure distributions of three cohorts between 1997 and 2005. For the oldest cohort we examine (born in 1912), mean and median expenditures increased by 7.5 percent and 3.9 percent per annum, which was less than the analogous increases for the 1922 and 1932 birth cohorts. The sharpest increases occurred for the youngest (born in 1932) cohort's expenditure distribution. Its median expenditures went up by 10.9 percent per annum.

Figures 13.1 and 13.2 organize these data visually using the smoothing technology that we describe in the methods section. In these figures, we plot both the age-expenditure profile in 2001 and the cohort-specific trends for the 1912, 1922, and 1932 cohorts in each year between 1997 and 2005. Figure 13.1 plots these objects at the ninetieth, ninety-fifth, and ninety-ninth percentiles, while figure 13.2 plots them at the mean and median. In each case, the cohort profiles are steeper than the age-expenditure profiles. For instance, the ninety-ninth percentile of expenditures for seventy-nine-yearolds in 2001 was less than the ninety-ninth percentile for seventy-nineyear-olds in 2002. It is evident from these figures and from table 13.4 that the youngest cohorts experienced the sharpest growth in Medicare expenditures.

The fact that the population of the oldest old experienced the smallest increases in per capita Medicare expenditures is consistent with the finding 


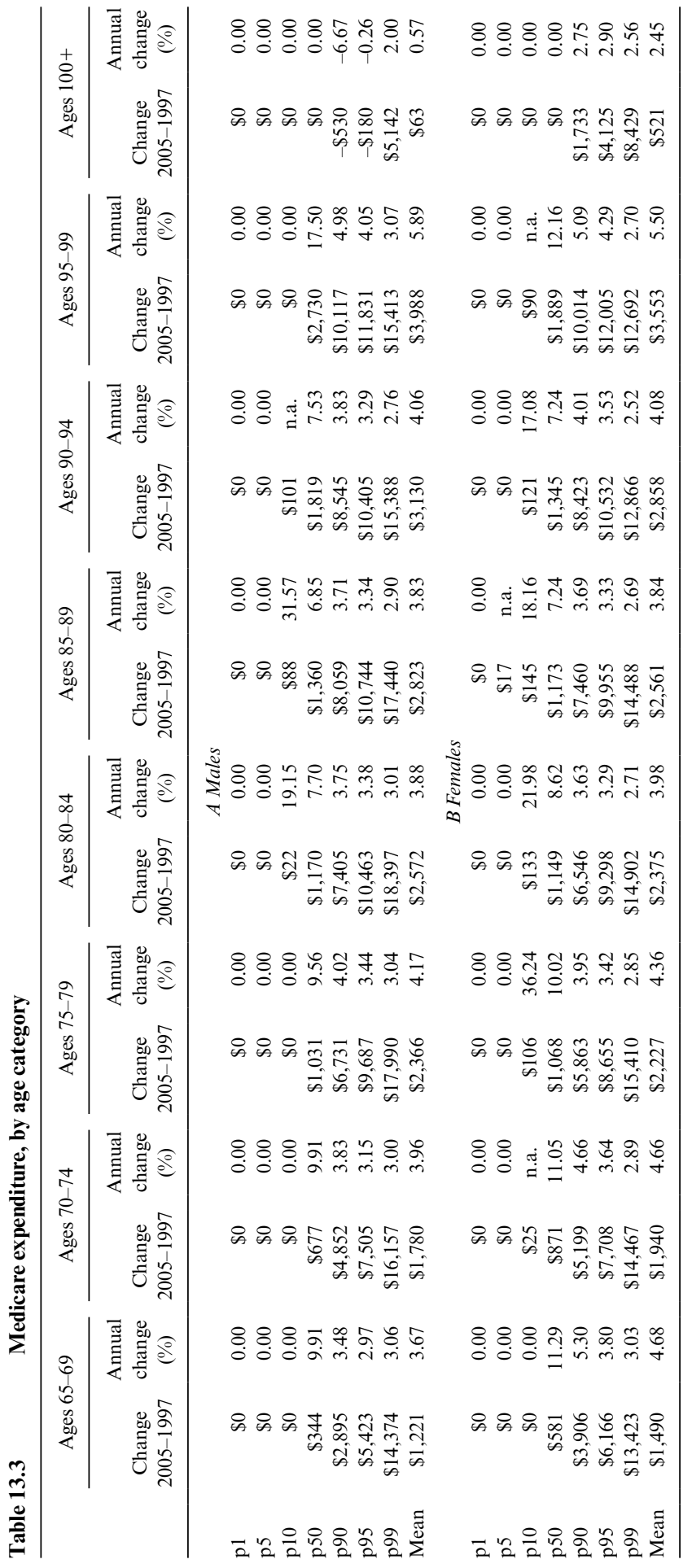


Medicare expenditure by year and cohort (selected years)

\begin{tabular}{|c|c|c|c|c|c|c|c|c|}
\hline Year & $\mathrm{p} 1$ & p5 & $\mathrm{p} 10$ & p50 & p90 & p95 & p99 & Mean \\
\hline \multicolumn{9}{|c|}{ Born in 1912} \\
\hline 1997 & $\$ 0$ & $\$ 0$ & $\$ 37$ & $\$ 1,572$ & $\$ 22,191$ & $\$ 33,641$ & $\$ 63,468$ & $\$ 7,322$ \\
\hline 2000 & $\$ 0$ & $\$ 0$ & $\$ 67$ & $\$ 1,704$ & $\$ 21,200$ & $\$ 32,364$ & $\$ 62,752$ & $\$ 7,139$ \\
\hline 2002 & $\$ 0$ & $\$ 0$ & $\$ 111$ & $\$ 2,123$ & $\$ 24,555$ & $\$ 37,164$ & $\$ 70,256$ & $\$ 8,267$ \\
\hline 2005 & $\$ 0$ & $\$ 0$ & $\$ 154$ & $\$ 2,795$ & $\$ 29,718$ & $\$ 43,950$ & $\$ 79,846$ & $\$ 9,950$ \\
\hline Change 2005-1997 & $\$ 0$ & $\$ 0$ & $\$ 117$ & $\$ 1,223$ & $\$ 7,527$ & $\$ 10,309$ & $\$ 16,378$ & $\$ 2,629$ \\
\hline$\%$ Annual change & $0 \%$ & $0 \%$ & $19.5 \%$ & $7.5 \%$ & $3.7 \%$ & $3.4 \%$ & $2.9 \%$ & $3.9 \%$ \\
\hline \multicolumn{9}{|c|}{ Born in 1922} \\
\hline 1997 & $\$ 0$ & $\$ 0$ & $\$ 0$ & $\$ 825$ & $\$ 15,408$ & $\$ 27,793$ & $\$ 61,918$ & $\$ 5,323$ \\
\hline 2000 & $\$ 0$ & $\$ 0$ & $\$ 0$ & $\$ 1,078$ & $\$ 15,150$ & $\$ 27,137$ & $\$ 60,582$ & $\$ 5,397$ \\
\hline 2002 & $\$ 0$ & $\$ 0$ & $\$ 11$ & $\$ 1,354$ & $\$ 17,506$ & $\$ 30,997$ & $\$ 68,524$ & $\$ 6,248$ \\
\hline 2005 & $\$ 0$ & $\$ 0$ & $\$ 25$ & $\$ 1,797$ & $\$ 21,254$ & $\$ 36,463$ & $\$ 78,402$ & $\$ 7,496$ \\
\hline Change 2005-1997 & $\$ 0$ & $\$ 0$ & $\$ 25$ & $\$ 972$ & $\$ 5,846$ & $\$ 8,670$ & $\$ 16,484$ & $\$ 2,173$ \\
\hline$\%$ Annual change & $0 \%$ & $0 \%$ & n.a. & $10.2 \%$ & $4.1 \%$ & $3.5 \%$ & $3.0 \%$ & $4.4 \%$ \\
\hline \multicolumn{9}{|c|}{ Born in 1932} \\
\hline 1997 & $\$ 0$ & $\$ 0$ & $\$ 0$ & $\$ 267$ & $\$ 6,484$ & $\$ 16,142$ & $\$ 47,148$ & $\$ 3,009$ \\
\hline 2000 & $\$ 0$ & $\$ 0$ & $\$ 0$ & $\$ 354$ & $\$ 6,560$ & $\$ 15,804$ & $\$ 46,510$ & $\$ 3,069$ \\
\hline 2002 & $\$ 0$ & $\$ 0$ & $\$ 0$ & $\$ 472$ & $\$ 7,571$ & $\$ 17,952$ & $\$ 52,426$ & $\$ 3,526$ \\
\hline 2005 & $\$ 0$ & $\$ 0$ & $\$ 0$ & $\$ 612$ & $\$ 9,488$ & $\$ 21,578$ & $\$ 60,961$ & $\$ 4,237$ \\
\hline Change 2005-1997 & $\$ 0$ & $\$ 0$ & $\$ 0$ & $\$ 346$ & $\$ 3,003$ & $\$ 5,437$ & $\$ 13,813$ & $\$ 1,228$ \\
\hline$\%$ Annual change & $0 \%$ & $0 \%$ & $0 \%$ & $10.9 \%$ & $4.9 \%$ & $3.7 \%$ & $3.3 \%$ & $4.4 \%$ \\
\hline
\end{tabular}

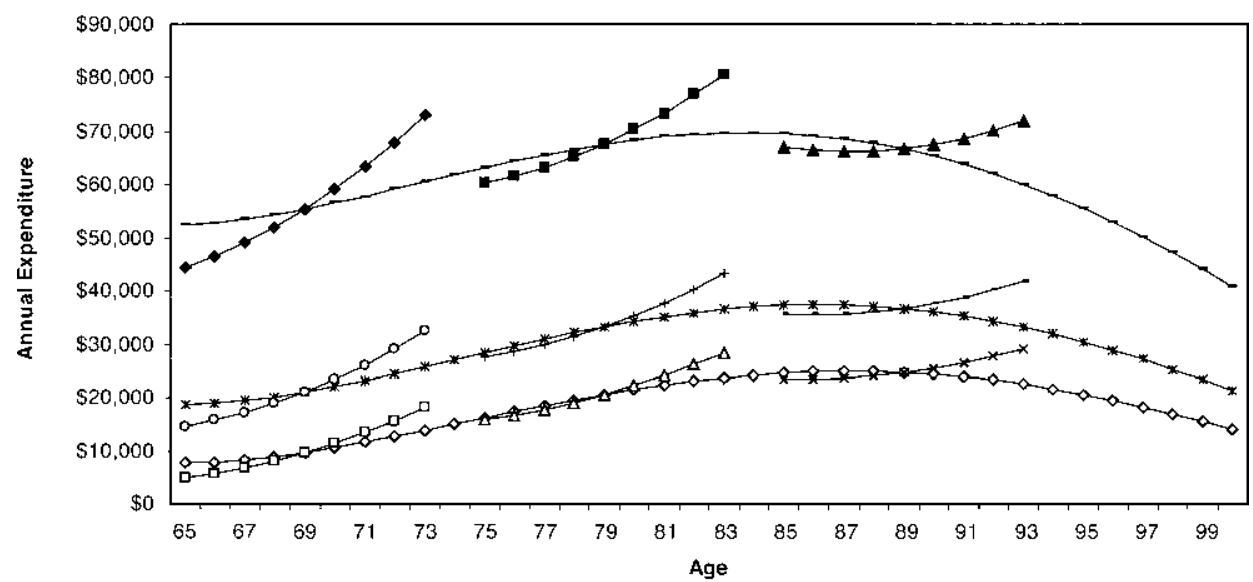

$\rightarrow$-Cross-section 2001, 90th Perc. - $\square-$ Cohor 1932, 90th Perc.
* Cross-section 2001, 95th Perc. -o- Cohor 1932, 95th Perc.
— Cross-section 2001, 99th Perc. - Cohor 1932, 99th Perc.

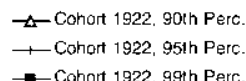

* Cohorl 1912, 90th Perc - Cohor 1912. 95th Pere $\rightarrow$ Cohort 1912, 9́sth Perc

Fig. 13.1 Smoothed annual Medicare expenditure, 1912, 1922, and 1932 cohorts-90th, 95th, and 99th percentiles 


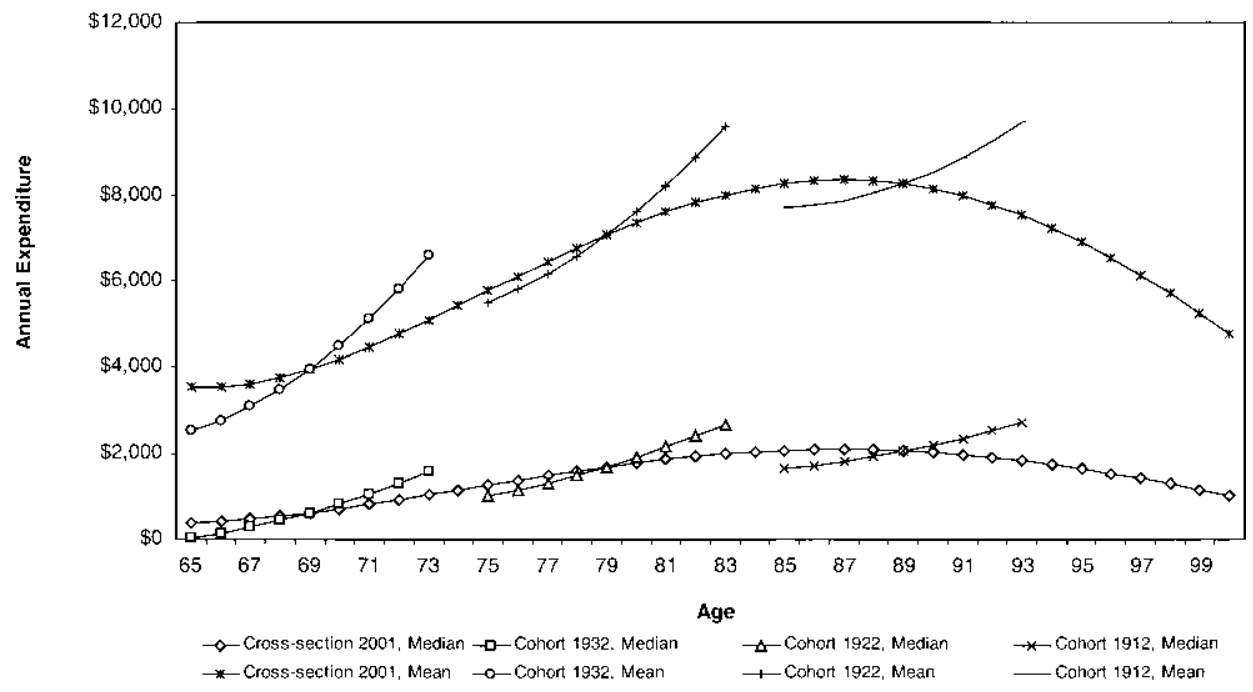

Fig. 13.2 Smoothed annual Medicare expenditure, 1912, 1922, and 1932 cohorts-median and mean

reported by Manton, $\mathrm{Gu}$, and Lamb (2006) that this group has experienced a decline in disability prevalence over this period. Disabled individuals are substantially more likely than nondisabled individuals to have high Medicare expenditures (see Goldman et al. 2005). Similarly, the fact that the youngest cohorts have experienced the sharpest increases in per capita Medicare expenditures is consistent with the finding reported by Lakdawalla, Bhattacharya, and Goldman (2004) that disability rates have been increasing over parts of this period in the near-elderly population. As these near-elderly individuals age into Medicare, they will naturally raise per capita expenditures for the youngest Medicare enrollees.

One conclusion suggested by the numbers in table 13.2 is that men and women had similar increases in per capita Medicare expenditures even if the distribution of expenditures for men shifted to the right a bit more than the distribution for women. Tables 13.3 and 13.4 show that the latter impression is an artifact of the age distribution of men and women in the Medicare program. Since men, on average, die at earlier ages than women, the proportion of women in the population who are older than eighty-five years of age is larger than the analogous proportion for men. Of course, we have seen that older populations had smaller increases in per capita Medicare expenditures over this period. So comparisons between men and women that are unadjusted for age, such as table 13.2, will be biased toward showing greater increases in expenditures for men than for women just because Medicare men tend to be younger than Medicare women. 
We turn next to a discussion of the role of chronic disease in explaining the changes in the distribution of Medicare expenditures. To set the stage for this discussion, we present table 13.5, which shows the prevalence of various chronic conditions in subgroups of the Medicare population averaged over the whole 1997 to 2005 period. The most common chronic conditions in the Medicare population include cataracts (27.95 percent of the population), coronary atherosclerosis (20.85 percent), atrial fibrillation (16.69 percent), and diabetes (16.04 percent). The low prevalence of cancer survivors in the Medicare population-for example, only 1.9 percent have a history of lung/GI cancer-is explained by the high mortality rate among Medicare cancer patients in the year of diagnosis (see Bhattacharya, Garber, and Miller 2006).

Table 13.5 also reports changes in the prevalence of chronic disease between 1997 and 2005. For nearly every chronic condition we examine, there was a rise in disease prevalence reflecting the aging of the Medicare population over this period. The largest prevalence increases relative to the 1997 baseline were for renal disease (93.4 percent increase over the period), osteoporosis (96.4 percent increase), osteoarthritis (57.0 percent increase), depression (53.2 percent increase), diabetes (37.6 percent increase), and dementia (35.5 percent increase). Several conditions - unstable angina, cataracts, myocardial infarction, stroke, and hip fracture/dislocation - actually declined in frequency over the period. Qualitatively, the pattern of changes in disease frequency was similar for men and women.

Chronic disease prevalence increases show no obvious relation to changes in the distribution of per capita Medicare expenditures shown on the right side of table 13.6. For instance, myocardial infarction (heart attacks), which decreased in prevalence over this period, had a sharp $\$ 1,350$ increase in mean expenditures. By contrast, mean expenditures on cataracts, which also showed a decrease in prevalence, had a modest $\$ 260$ increase over the period. Conversely, the average expenditures on osteoporosis patients, which saw large increase in prevalence, had the lowest increase in mean per capita expenditures (\$144). For nearly every condition we examine, expenditures toward the lower end of the expenditure distribution grew sharply, while expenditures toward the upper tails increased less sharply. That no one with a chronic condition had zero expenditures is an artifact of the way in which the chronic disease indicators are constructed - we inferred the presence of a chronic disease from claims files, so a claim (and hence expenditures) were required to detect chronic disease.

\subsection{Conclusions}

After 1997, the growth in expenditures among the highest percentiles of users of Medicare-reimbursed care was less than the rate of growth at the lower percentiles (among those with any expenditures at all). Thus, the 


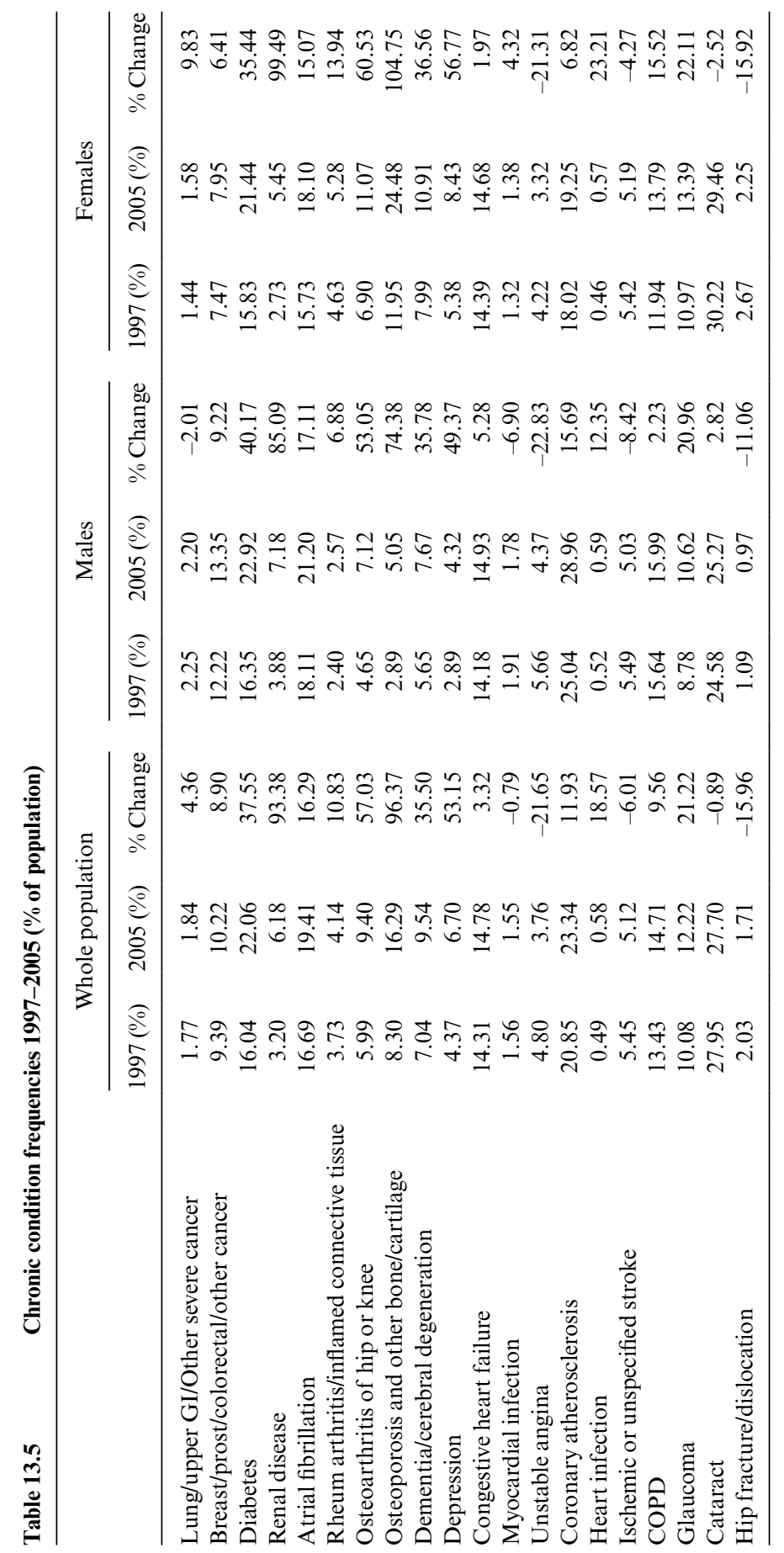




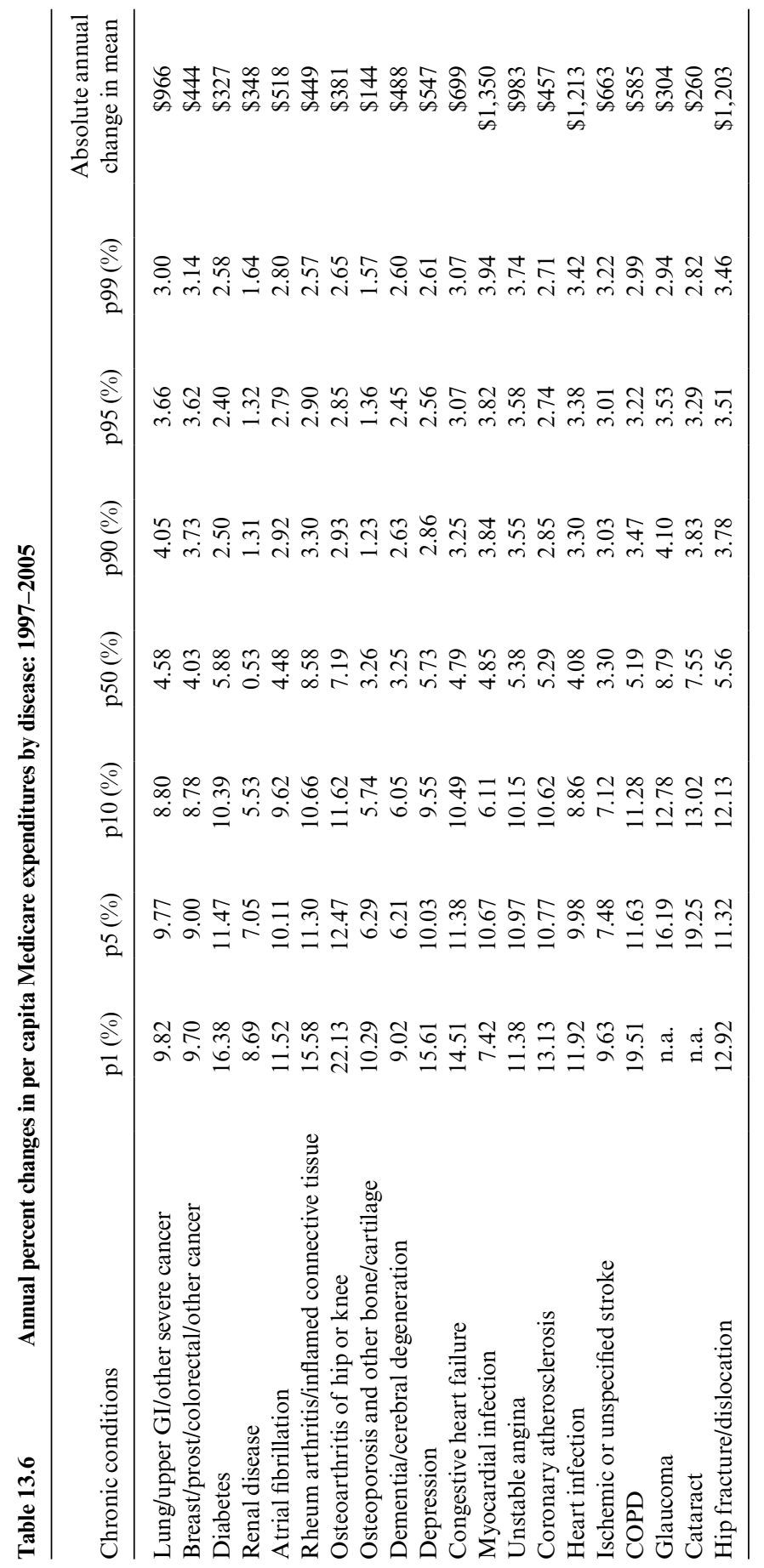


overall dispersion in expenditures fell over time. This trend was diminished, at least temporarily, after the implementation of the BBRA. These findings suggest that the main effects of the BBA of 1997 came about as expected. Admission to the hospital - even once in a year - is enough to move a beneficiary into a relatively high expenditure category. Most of the provisions of the BBA that were likely to lead to immediate reductions in expenditures, such as the revisions to hospital payments, would have had greatest impact on high-cost beneficiaries. Other nonhospital provisions, such as restrictions on home health service payments, would also affect primarily high-cost users. The provisions that might lead to long-term expenditure reductions for beneficiaries who do not use inpatient or outpatient services heavily, such as those who are relatively young and do not have chronic diseases, did not necessarily have large effects in the near term. For example, a shift to prospective payment for outpatient services might reduce payments for office visits in the long term, but typically a transition to such a payment system includes relatively generous payments initially. These changes, of course, depend not only on the mechanism of payment but the level of payment.

Changes in expenditures varied by age and other characteristics. A great deal of compression in the expenditure distribution occurred at advanced ages: cross-sectional analyses reveal that expenditures increased least sharply on average for the oldest beneficiaries. Though cohort growth rates outpaced the cross-sectional growth in expenditures for every cohort we examined, younger cohorts had sharper increases than the oldest cohort. These changes reflect a variety of influences, an important one being reductions in payments for home health services, which are disproportionately used by the very old. They also reflect, to a large degree, changes in disability and disease prevalence in the these populations.

Although there are important differences between expenditures for men and women, who have different levels of expenditures, the trends in expenditure growth rates were similar for both. By contrast, post-BBA expenditure growth for blacks at the upper percentiles and at the mean of expenditures was lower than for whites. Throughout the time period, mean, median, ninetieth, and ninety-fifth percentiles of expenditures for blacks were generally greater than the levels for whites, which is consistent with the worse health of blacks on average.

Although these results cannot be definitively traced to any specific aspects of policy, they followed a far-reaching attempt to limit the growth of Medicare expenditures. They suggest that expenditure growth was altered most in the areas targeted by BBA. They also suggest that piecemeal changes - those that target only some components of Medicare-cannot be assumed to control overall expenditure growth, since substitution of services can offset some of the savings. In the case of the BBA, the appropriate concentration on high expenditures is likely to have led to a compression of the expenditure distribution, which has implications for all policies that depend upon not 
only the level of expenditures but their variance, a critical consideration in expansions of insurance coverage.

\section{References}

Bhattacharya, J., A. M. Garber, and T. MaCurdy. 1997. Cause-specific mortality among Medicare enrollees. In Inquiries in the economics of aging, ed. D. Wise, 311-26. Chicago: University of Chicago Press.

Bhattacharya, J., A. M. Garber, and Miller. 2006. Progress against cancer among elderly Americans. Stanford University. Unpublished Manuscript.

Bhattacharya, J., and D. Lakdawalla. 2006. Does Medicare benefit the poor? Journal of Public Economics 90 (1-2): 277-92.

Fisher, E. S., J. E. Wennberg, T. A. Stukel, and S. M. Sharp. 1994. Hospital readmission rates for cohorts of Medicare beneficiaries in Boston and New Haven. New England Journal of Medicine 331 (15): 989-95.

Fisher, E. S., F. S. Whaley, W. M. Krushat, D. J. Malenka, C. Fleming, J. A. Baron, and D.C. Hsia. 1992. The accuracy of Medicare's hospital claims data: Progress has been made, but problems remain. American Journal of Public Health 82 (2): 243-8.

Garber, A., and T. MaCurdy. 1993. Nursing home discharges and the exhaustion of Medicare benefits. Journal of the American Statistical Association 88:727-36.

Goldman, D. P., B. Shang, J. Bhattacharya, A. M. Garber, M. Hurd, G. F. Joyce, D. Lakdawalla, C. Panis, and P. Shekelle. 2005. Health and spending of the future elderly: Consequences of health trends and medical technology. Health Affairs. Web Exclusive, 26 September.

Hsia, D.C., M. Kurushat, A. B. Fagan, J. A. Tebbutt, and R. P. Kusserow. 1988. Accuracy of diagnostic coding for Medicare payments under the prospectivepayment system. New England Journal of Medicine 318:352-5.

Iezzoni, L. I., S. Burnside, L. Sickles, M. A. Moskowitz, E. Sawitz, and P. A. Levine. 1988. Coding of acute myocardial infarction: Clinical and policy implications. Annals of Internal Medicine 109 (9): 745-51.

Institute of Medicine. 1977a. Reliability of hospital discharge abstracts. Washington, DC: National Academy of Sciences.

1977b. Reliability of Medicare hospital discharge records. Washington, DC: National Academy of Sciences.

1980. Reliability of national hospital discharge survey data. Washington, DC: National Academy of Sciences.

Koenker, R., and K. Hallock. 2001. Quantile regression. Journal of Economic Perspectives 15:143-56.

Lakdawalla, D., J. Bhattacharya, and D. Goldman. 2004. Are the young becoming more disabled? Health Affairs 23 (1): 168-76.

Manton, K. G., X. Gu, and V. L. Lamb. 2006. Change in chronic disability from 1982 to 2004/2005 as measured by long-term changes in function and health in the U.S. elderly population. Proceedings of the National Academy of Science 103 (48): 18374-9.

MaCurdy, T., and J. Geppert. 2005. Characterizing the experiences of high-cost users in Medicare. In Analyses in the economics of aging, ed. D Wise, 79-128. Chicago: University of Chicago Press. 
MaCurdy, T., D. Green, and H. J. Paarsch. 1990. Assessing empirical approaches for analyzing taxes and labor supply. Journal of Human Resources 25 (3): 415-90.

Mark, D. H. 1994. Mortality of patients after radical prostatectomy: Analysis of recent Medicare claims. Journal of Urology 152 (3): 896-8.

May, D. S., and S. J. Kittner. 1994. Use of Medicare claims data to estimate national trends in stroke. Stroke 25 (12): 2343-7.

McBean, A. M., J. D. Babish, and J. L. Warren. 1993. Determination of lung cancer incidence in the elderly using Medicare claims data. American Journal of Epidemiology 137 (2): 226-34.

McBean, A. M., J. L. Warren, and J. D. Babish. 1994. Measuring the incidence of cancer in elderly Americans using Medicare claims data. Cancer 73 (9): 2417-25.

Peterson, E. D., J. G. Jollis, J. D. Bebchuk, E. R. DeLong, L. H. Muhbaier, D. B. Mark, and D. B. Pryor. 1994. Changes in mortality after myocardial revacularization in the elderly: The national Medicare experience. Annals of Internal Medicine 121 (12): 919-27.

Pope, G. C., J. Kautter, R. P. Ellis, A. S. Ash, J. Z. Ayanian, L. I. Iezzoni, M. J. Ingber, J. M. Levy, and J. Robst. 2004. Risk adjustment of Medicare capitation payments using the CMS-HCC model. Health Care Financing Review 25 (4): $119-41$.

Udvarhelyi, I. S., C. Gatsonis, A. M. Epstein, C. L. Pashos, J. P. Newhouse, and B. J. McNeil. 1992. Acute myocardial infarction in the Medicare population: Process of care and clinical outcomes. Journal of the American Medical Association 268 (18): 2530-6.

Whittle, J., E. P. Steinberg, G. F. Anderson, and R. Herbert. 1991a. Accuracy of Medicare claims data for estimation of cancer incidence and resection rates among elderly Americans. Medical Care 29 (12): 1226-36.

1991b. Use of Medicare claims data to evaluate the outcomes of elderly patients undergoing lung resection for lung cancer. Chest 100:729-34.

. 1992. Results of colectomy in elderly patients with colon cancer, based on Medicare claims data. American Journal of Surgery 163 (6): 572-6.

Wilensky, G. 2000. The Balanced Budget Act of 1997: A current look at its impact on patients and providers. Testimony before the Subcommittee on Health and Environment, Committee on Commerce, U.S. House of Representatives. July 19.

\section{Comment Jonathan Skinner}

A key to solving the problem of runaway growth in the U.S. Medicare program's expenditures (and for health care expenditures more generally) is a better understanding of the dynamic process by which health care costs continue their march upward. Yet little is known about patterns of growth, nor do we know who is actually receiving the additional care. So this study

Jonathan Skinner is the John Sloan Dickey Third Century Professor in Economics at Dartmouth College, professor of community and family medicine at Dartmouth Medical School, and a research associate of the National Bureau of Economic Research. 